\title{
INFLUENCE OF REARING SYSTEM ON PERFORMANCE OF CAMEL CALVES
}

\author{
Champak Bhakat ${ }^{1}$, Nirmala Saini and K.M.L. Pathak \\ National Research Centre on Camel, Jorbeer, Bikaner, 334001 , \\ Rajasthan, India
}

(Received : 24-10-2008; Accepted : 10-09-2009)

\begin{abstract}
Presently, farmers are inclined to rear their camels in intensive and semi-intensive rearing systems indicating a shift from extensive rearing system. The present study was conducted to investigate the influence of rearing system on performances, level of important and relevant macro and micro minerals and interventions in camel calves rearing.
\end{abstract}

\section{Materials and Methods}

Ten camel (Camelus dromedarius) calves, about 7-10 months of age belonging to N.R.C on Camel, Bikaner were allotted randomly into two groups of two different rearing systems. The first group was kept under intensive rearing system (IRS) with concentrate supplementation @ $1 \mathrm{~kg} / \mathrm{calf} /$ day. The second group was kept under semiintensive rearing system (SIRS) with provision of grazing / browsing daily for about 6 to 7 hours and offered fodder in the evening. Each group contained one Bikaneri, three Jaisalmeri, one Kutchi breed comprised by four males and one female. The manger feeding consisting of moth chara (Phaseolus aconitifolius) was given in both rearing systems as per standard feeding schedule followed at NRCC farm. Daily once watering was done for all camel calves in both groups. Camel hair accumulates all important minerals and is commonly available tissue which can easily be collected, stored and transported. At end of the experiment hair samples were collected from shoulder, neck, hump and mid region of body of camel calves. The hair was cut with stainless steel scissors into pieces of about $1 \mathrm{~cm}$ in length from each region and mixed well to ensure homogeneity. The samples were washed with acetone and then filtered and rinsed with adequate deionized water. The samples were dried and $0.5 \mathrm{gm}$ of dried sample was taken for further processing. The body weight of calves was recorded first before shifting calves to respective treatments and thereafter weighed at fortnightly intervals. The average weight of two consecutive days was taken to represent fortnightly body weight. The weighing was always done in the morning before offering feed or water. Body weight formed basis of determining growth rate of camels. For analysis of hair minerals status Brown and Taylor (1995) method was used. The concentration of different elements was aetermined by. Atomic Absorption Spectrophotometer. For statistical analysis paired - $t$ test (Snedecor and Cochran 1989) was applied between two rearing systems. The economic analysis of rearing of camel calves in different systems was done by considering the feed cost.

${ }^{1}$ Corresponding author : e-mail : bhakat@scientist.com 


\section{Results and Discussion}

The performance of camel calves in different rearing systems is presented in the table. After 170 days of trial period, mean body weight was significantly $(P<0.01)$ increased in intensive rearing system as compared to semi-intensive rearing system. The total gain was higher in intensive rearing than semi-intensive rearing group at end of the trial. The average growth rate was significantly $(P<0.01)$ higher in intensive rearing as compared to semi-intensive rearing. The average fodder intake (from manger) per calf per day was found to be on higher side in case of intensive compared to semi-intensive rearing group. Bhakat and Nagpaul (2005) had reported that despite similar dry matter content of fodder the intake in all groups were different which is due to the difference in the types of housing provided to animals.

The analysis of performance data under intensive rearing system revealed that average total dry matter intake (DMI) was $5.06 \pm 0.63$ $\mathrm{kg} / \mathrm{calf} / \mathrm{day}$. The ratio between water intake and DMI was $2.34 \pm 0.27$. The average feed conversion efficiency was $10.98 \pm 0.82$. The total DMI per $100 \mathrm{~kg}$ body weight was $2.25 \pm$ $0.34 \mathrm{~kg} / \mathrm{calf}$. Total intake per day per $\mathrm{kg}$ metabolic body size was $0.089 \pm 0.008 \mathrm{~kg}$. The average water intake was more in case of intensive rearing as compared to semiintensive rearing group. Khanna et al. (1990) reported correlation between body weight and measurements in Bikaneri, Jaisalmeri, Kutchi and Mewari breed of camels.

In the present study the calcium was significantly $(P<0.05)$ higher in IRS as compared to SIRS. The level of calcium varied from 690 to $870 \mu \mathrm{g} / \mathrm{g}$ in IRS where as in SIRS it varied from 193.6 to $806 \mu \mathrm{g} / \mathrm{g}$. The level of magnesium varied from 53.2 to $67.2 \mu \mathrm{g} / \mathrm{g}$ in IRS where as in SIRS, it varied from 53.6 to $60 \mu \mathrm{g} / \mathrm{g}$. Kayar et al. (2004) reported that levels of some elements are affected to a higher or lower degree by nutritional differences in horse. In the present study the average copper level was significantly $(P<0.05)$ higher in SIRS as compared to IRS group. The level of copper varied from 2.03 to $6.8 \mu \mathrm{g} / \mathrm{g}$ in IRS where as in SIRS it varied from 5.2 to $9.6 \mu \mathrm{g} / \mathrm{g}$. Non significantly higher average zinc level was found in SIRS than IRS. The level of zinc varied from 43.7 to $59 \mu \mathrm{g} / \mathrm{g}$ in IRS where as in SIRS it varied from 50.6 to $62.8 \mu \mathrm{g} / \mathrm{g}$. Average level of iron and manganese was significantly $(P<$ $0.05)$ higher in IRS than in SIRS. The level of iron widely varied from 235 to $328 \mu \mathrm{g} / \mathrm{g}$ and from 224 to $278.2 \mu \mathrm{g} / \mathrm{g}$ in IRS and SIRS, respectively. The level of manganese ranged from 29.4 to $63.4 \mu \mathrm{g} / \mathrm{g}$ in IRS where as in SIRS, it varied from 18 to $32.8 \mu \mathrm{g} / \mathrm{g}$.

All items of cost for camel calves rearing were similar except feeding cost (Table). The total feeding cost (in Rs.) per calf for 170 days was more in IRS as compared to SIRS. The total feeding cost per day per calf was higher.in IRS than SIRS group. Total cost for one $\mathrm{kg}$ body weight gain was quite less in intensive rearing as compared to semi-intensive rearing group. Since total body weight gain and average growth rate were quite high, in intensive rearing group, it was more economical than semi-intensive rearing group.

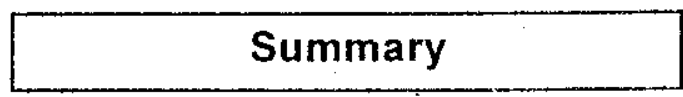

Ten camel calves were allotted randomly into two groups of intensive rearing system (IRS) and semi-intensive rearing system (SIRS) for 170 days experimentation. After 170 days of trial period, mean body weight and growth rate were significantly $(P<0.01)$ higher in IRS as 
Table : Performance of camel calves and economics in different systems of rearing.

\begin{tabular}{|c|c|c|c|}
\hline Tree leaves & $\begin{array}{l}\text { Thtensive rearing } \\
\text { system (IRS) }\end{array}$ & & $\begin{array}{l}\text { Semi-intensive rearing } \\
\text { system (SIRS) }\end{array}$ \\
\hline Average body weight after 170 days $(\mathrm{kg})$ & $266.60 \pm 12.93$ & *⿻ & $216.60 \pm 14.74$ \\
\hline Initial average body weight $(\mathrm{Kg})$. & $170.00 \pm 12.08$ & NS & $165.00 \pm 13.61$ \\
\hline Total gain in body weight (Kg.) & 96.60 & & 51.60 \\
\hline Average daily gain (gm / day) & $545.18 \pm 37.24$ & *\# & $339.51 \pm 48.12$ \\
\hline $\begin{array}{l}\text { Average moth chara intake (manger) } \\
\mathrm{kg} / \text { calf / day }\end{array}$ & $5.33 \pm 0.74$ & NS & $5.12 \pm 0.68$ \\
\hline $\begin{array}{l}\text { Average water intake (trough) } \\
\mathrm{kg} / \text { calf / day }\end{array}$ & $11.86 \pm 1.54$ & NS & $11.73 \pm 1.97$ \\
\hline \multicolumn{4}{|l|}{ Economic analysis : } \\
\hline Total feeding cost for 170 days (Rs. / calf) & 304.53 & & 2001.92 \\
\hline Daily feeding cost (Rs. / calf) & 17.90 & & 11.78 \\
\hline Total cost for one $\mathrm{kg}$ body weight gain (Rs.) & 31.52 & & 38.79 \\
\hline
\end{tabular}

** Significant at $1 \%$, NS : Non-significant compared to SIRS. Analysis of hair mineral status revealed significant difference IRS and SIRS groups. The total feeding cost per calf for 170 days was more in IRS as compared to SIRS group. Total cost for one $\mathrm{kg}$ body weight gain was quite less in IRS rearing system showed better results than semi-intensive rearing system for economic camel calf management.

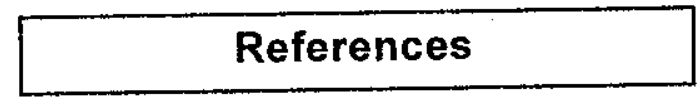

Bhakat, C and Nagpaul, P.K. (2005). Indian J. Anim. as compared to SIRS group. Intensive
Sci. $75: 69$. Atomic Spectrometry $110: 579$.

Kayar, ME., Maden, A., Gulyasar, D., Tosun, R and Dourka, C., (2004). Nigerian Vet. J. $25: 9$.

Khanna, N.D, Rai, A.K and Tandon, S.N. (1990), Indian J: Anim. Sci:, $60: 1347$.

Snedecor, W G and Cochran GW. (1989). Statistical methods. Oxford and $1 B H$ publishing Co. Pvt. Ltd. New Delhi, India.

Tommasco, P.M. (1998). Biol. Trace Elem. Research $62: 214$.
Brown, A.A and Taylor, A. (1995). J. Analytic

THE I IN PEL

B.K. Ro

Banglade:

The $\mathrm{c}$ rations utili: industrial by feeding sys production. undertaken tc of various rous on the growth, goats.

goats.

Mater

Twenty goats $(4-9$ n goat and sheef BLRI, Dhaki homogenous t in individual pe floor equippes waterer.

Five dief diet A (CBP) composed of meal, molas phosphate, vith salt, no anima diet; diet $\mathrm{B}$ (C) based pellet) ingredients (commercial of soybean $m^{2}$ $C, D$ and $E$ w

${ }^{1}$ Corresponding 